\title{
1 Removal of chlorinated organic solvents from hydraulic fracturing \\ 2 wastewater by bare and entrapped nanoscale zero-valent iron
}

4 Cheng Lei ${ }^{1,2}$, Yuqing Sun ${ }^{2,3}$, Eakalak Khan ${ }^{4}$, Season S. Chen², Daniel C.W. Tsang ${ }^{2, *}$, Nigel

5 J.D. Graham ${ }^{5}$, Yong Sik Ok ${ }^{6}$, Xin Yang ${ }^{7}$, Daohui Lin ${ }^{1,}{ }^{*}$, Yujie Feng ${ }^{3}$, Xiang-Dong Li ${ }^{2}$

6

$7 \quad{ }^{1}$ Department of Environmental Science, Zhejiang University, Hangzhou 310058, China

$8{ }^{2}$ Department of Civil and Environmental Engineering, The Hong Kong Polytechnic University, Hung Hom,

9 Kowloon, Hong Kong, China

$10{ }^{3}$ State Key Laboratory of Urban Water Resource and Environment, Harbin Institute of Technology, Harbin

11 150090, China

$12{ }^{4}$ Civil and Environmental Engineering Department, North Dakota State University, Dept 2470, P.O. Box

13 6050, Fargo, ND 58108, USA

$14{ }^{5}$ Environmental and Water Resources Engineering, Department of Civil and Environmental Engineering,

15 Imperial College London, South Kensington, London, SW7 2AZ, UK

$16{ }^{6}$ Korea Biochar Research Center, O-Jeong Eco-Resilience Institute (OJERI) \& Division of Environmental

17 Science and Ecological Engineering, Korea University, Seoul 02841, Republic of Korea.

$18{ }^{7}$ School of Environmental Science and Engineering, Sun Yat-sen University, Guangzhou 510275, China.

$19 *^{*}$ Corresponding author (email: dan.tsang@polyu.edu.hk).

$20 *$ Co-corresponding author (email: $\underline{\text { lindaohui@zju.edu.cn). }}$ 


\section{Abstract}

With the increasing application of hydraulic fracturing, it is urgent to develop an effective and economically feasible method to treat the large volumes of fracturing wastewater. In this study, bare and entrapped nanoscale zero-valent iron (nZVI) were introduced for the removal of carbon tetrachloride (CT) and 1,1,2-trichloroethane (TCA) in model high-salinity fracturing wastewater. With increasing ionic strength $(I)$ from Day-1 $(I=0.35 \mathrm{M})$ to Day-90 $(I=4.10 \mathrm{M})$ wastewaters, bare nZVI presented significantly lower removal efficiency of CT (from 53.5\% to 38.7\%) and 1,1,2-TCA (from $71.1 \%$ to $21.7 \%$ ) and underwent more serious Fe dissolution from $1.31 \pm 1.19 \%$ in Day-1 to $5.79 \pm 0.32 \%$ in Day-90 wastewater. Particle aggregation induced by high ionic strength was primarily responsible for the lowered performance of nZVI due to less available reactive sites on nZVI surface. The immobilization of nZVI in alginate with/without polyvinyl alcohol provided resistance to particle aggregation and contributed to the superior performance of entrapped nZVI in Day-90 wastewater for 1,1,2-TCA removal (62.6-72.3\%), which also mitigated Fe dissolution (4.00-4.69\%). Both adsorption (by polymer matrix) and reduction (by immobilized nZVI) were involved in the 1,1,2-TCA removal by entrapped nZVI. However, after 1-month immersion in synthetic fracturing wastewater, a marked drop in the reactivity of entrapped nZVI for 1,1,2-TCA removal from Day-90 wastewater was observed with significant release of $\mathrm{Na}$ and total organic carbon. In summary, bare nZVI was sensitive to the nature of the fracturing wastewater, while the use of environmentally benign entrapped nZVI was more promising for wastewater treatment.

Keywords: nZVI; alginate entrapment; 1,1,2-trichloroethane; carbon tetrachloride; iron dissolution; fracturing wastewater treatment. 


\section{Introduction}

44 Hydraulic fracturing is a method to enhance unconventional oil and gas production, which is being 45 increasingly used, especially in the United States (Stringfellow et al., 2014). However, considerable concerns on the potential environmental and health impacts of the process have been raised (Chen et al., 2016; Yost et al., 2016). The production of large volumes of fracturing wastewater (FWW) $\left(\sim 5,000 \mathrm{~m}^{3}\right.$ each well) is one of the principal aspects of concern, as FWW contains extremely high concentrations of salts (up to $350,000 \mathrm{mg} \mathrm{L}^{-1}$ ), toxic metals/metalloids, radionuclides, and various organic constituents (Abualfaraj et al., 2014). A recent toxicity study based on real FWW indicated that rainbow trout (Oncorhynchus mykiss) could suffer from oxidative stress and endocrine disruption with the exposure to FWW (He et al., 2017), and chronic exposure to FWW could result in reproduction toxicity on Daphnia magna (Blewett et al., 2017). Hence, FWW should be properly treated prior to its reuse or final release into the environment.

Deep-well injection for FWW disposal has become less feasible due to the limited available injection sites and the pressure from the public for a more sustainable solution (Lutz et al., 2013). In recent years, conventional and advanced technologies have been put forward to treat the wastewater to a higher quality, especially membrane-based processes (Estrada and Bhamidimarri, 2016; Silva et al., 2017). However, severe membrane fouling induced by FWW, technical limitations (e.g., total dissolved solids (TDS) should be lower than $40 \mathrm{~g} \mathrm{~L}^{-1}$ for reverse osmosis, and membrane distillation could not remove volatile organic compounds), and high capital and operating costs have limited their widespread application (Gregory et al., 2011; Silva et al., 2017). 
65 Membrane bioreactor (MBR) technology, a combination of membrane separation and microbial

66 transformation, is considered as a promising alternative and has been applied widely for municipal

67 and industrial wastewater treatment (Sharghi and Bonakdarpour, 2013). The process with a

68 halophilic bacterial consortium was able to remove 83-93\% COD of hypersaline synthetic FWW

69 (Sharghi and Bonakdarpour, 2013). However, high organic loads, a common characteristic of FWW,

70 can induce membrane fouling and reduce sludge settling in the MBR process (Silva et al., 2017).

71 The presence of excessive amounts of toxic contaminants could also suppress microbial activity. To

72 overcome these limitations, a pre-treatment method could be introduced to partially remove the

73 organics and metal/metalloid contaminants and thereby provide a better environment for microbial

74 growth.

76 Due to the large surface area and unique catalytic activity, nanoscale zero-valent iron (nZVI) has

77 been widely used for in situ soil and groundwater remediation (Yan et al., 2013; Stefaniuk et al.,

78 2016). In addition to high removal capacity for metals/metalloids (e.g., $\mathrm{Cu}, \mathrm{Zn}, \mathrm{Cr}$, and As), nZVI

79 degrades a variety of organic compounds by chemical reduction, such as chlorinated organic

80 compounds (Yan et al., 2013; Adeleye et al., 2016), which has been observed in FWW. Previous

81 study demonstrated that nZVI could reduce 67\% COD at circumneutral $\mathrm{pH}(7.5)$ and $85 \%$ toxicity

82 in recalcitrant waste metalworking fluids, making the effluent more amenable for subsequent

83 biological treatment (Jagadevan et al., 2012). Ma and Zhang (2008) integrated nZVI process with

84 biological treatment at a full-scale application, which presented an efficient COD removal from

85 industrial wastewater and contributed to process stability and microbial growth. Thus, nZVI could

86 be a potential candidate for FWW pretreatment followed by biological treatment, such as by an 
MBR process.

However, the application of bare nZVI powder may not be suitable for FWW treatment, owing to the possibility of particle aggregation in high ionic strength (Yan et al., 2013). Several strategies have been developed to stabilize nZVI, such as surface modification by polyelectrolytes, dispensing in an emulsified oil-water suspension, and immobilizing on a solid support (Crane and Scott, 2012; Lei et al., 2018). In order to minimize any potential toxicity effects, the immobilization of nZVI into a bio-based material could be a promising method to improve the application of nZVI in high-salinity FWW. Alginate, a natural biopolymer from marine brown algae, is nontoxic, biodegradable, non-immunogenic, and relatively insoluble in water, making it an ideal candidate for nZVI entrapment (Bezbaruah et al., 2014). Beads prepared from calcium alginate are sufficiently porous in nature to allow the contaminants to diffuse and make contact with entrapped nZVI. The immobilization of nZVI into calcium alginate beads has been successfully developed without reactivity sacrifice, as reflected by comparable performance with bare nZVI in nitrate, trichloroethene (TCE) and arsenic removal (Bezbaruah et al., 2009; Bezbaruah et al., 2011; Bezbaruah et al., 2014). Due to the rigid and fragile nature of crosslinked alginate, a flexible co-polymer, polyvinyl alcohol (PVA), was introduced to improve the durability and chemical stability (Lv et al., 2013). Previous studies investigated the reactivity of entrapped nZVI beads in background solution with low ionic strength, and/or evaluated the influence of single parameter (e.g., pH, nZVI dosage, and coexisting ions) (Bezbaruah et al., 2014; Liu et al., 2014; Chang et al., 2015), but not for wastewater with high ionic strength and various coexisting influencing factors. Our previous work has successfully applied entrapped nZVI for metal/metalloid removal from 
109 FWW, which promoted $\mathrm{Zn}(\mathrm{II})$ and $\mathrm{Cr}(\mathrm{VI})$ removal and mitigated Fe dissolution (Sun et al., 2017),

110 while the performance of entrapped nZVI for organic removal from FWW remains uncertain.

112 In this study, we evaluated the FWW treatment performance using both bare and entrapped nZVI

113 with model FWW containing two chlorinated organic solvents, carbon tetrachloride (CT) and

114 1,1,2-trichloroethane (TCA), as representative organic contaminants. The two organics are

115 carcinogenic and their mean concentrations detected in Marcellus Shale FWW were 9.5 times of

116 their maximum contamination level of $5 \mu \mathrm{g} \mathrm{L}^{-1}$ for drinking water, while their maximum

117 concentrations reached 2,000 $\mu \mathrm{g} \mathrm{L}^{-1}$ (Abualfaraj et al., 2014). The objectives of the study were to: (i)

118 investigate the relationship between FWW chemistry and organic degradation by bare nZVI; (ii)

119 examine the effectiveness of entrapped nZVI for organic removal; (iii) evaluate the aging effects on

120 the structure and reactivity of entrapped nZVI.

121

\section{2. Materials and methods}

1232.1 Chemicals

124 The chemicals used for preparing model FWW (viz. $\mathrm{NaOH}, \mathrm{HCl}, \mathrm{KCl}, \mathrm{NaBr}, \mathrm{BaCl}_{2} \cdot 2 \mathrm{H}_{2} \mathrm{O}$,

$125 \mathrm{CaCl}_{2} \cdot 2 \mathrm{H}_{2} \mathrm{O}, \mathrm{Fe}\left(\mathrm{NO}_{3}\right)_{3} \cdot 9 \mathrm{H}_{2} \mathrm{O}, \mathrm{SrCl}_{2} \cdot 6 \mathrm{H}_{2} \mathrm{O}, \mathrm{MgCl}_{2} \cdot 6 \mathrm{H}_{2} \mathrm{O}, \mathrm{NaCl}$, and $\left.\mathrm{H}_{3} \mathrm{BO}_{3}\right)$ were reagent grade

126 and obtained from Sigma Aldrich (USA). The initial $\mathrm{pH}$ of the model FWW was adjusted by using

$1270.1 \mathrm{M} \mathrm{HCl}$ or $\mathrm{NaOH}$. The $\mathrm{CT}$ and 1,1,2-TCA compounds were purchased from Accuchem (USA)

128 and Sigma Aldrich (USA). Methanol (99\%, Tedia Company, Inc., USA) for CT and 1,1,2-TCA

129 stock solution preparations and hexane (99\%, Sigma Aldrich, USA) for CT and 1,1,2-TCA

130 extractions were HPLC grade. Sodium alginate and PVA for nZVI entrapment were purchased from 
131 Sigma Aldrich (USA). Deionized water (DIW) from a Milli-Q water process was used in the

132 experiments.

133

$134 \quad 2.2$ Synthesis of fracturing wastewater

135 Model FWW in this study was synthesized based on Hayes (2009). Day-1, Day-14 and Day-90

136 FWW represented the wastewaters returning to the ground surface in 1, 14, and 90 days after well

137 creation, respectively. The median concentrations of major inorganic compounds were chosen as the

138 background levels as shown in our previous papers (Chen et al., 2017; Sun et al., 2017) and Table

139 S1. A desired amount of the CT and 1,1,2-TCA stock solutions (prepared in methanol at 2,000 $\mathrm{mg}$

$140 \mathrm{~L}^{-1}$ ) were spiked into the model FWW by a glass syringe to yield a final concentration of each

141 compound of $2 \mathrm{mg} \mathrm{L}^{-1}$, corresponding to the maximum concentration detected in Marcellus Shale

142 flowback water (Abualfaraj et al., 2014). The low concentration of methanol $(0.1 \% \mathrm{v} / \mathrm{v})$ in the

143 prepared FWW would not induce cosolvent effects or affect the experimental results.

$145 \quad 2.3$ Bare nZVI and entrapment of nZVI

146 Commercially available nZVI Nanofer STAR (Nanoiron, Ltd., Rajhrad, Czech Republic) was air

147 stable dry powder without surface modification, and had been used in our previous study (Sun et al.,

148 2017). According to the manufacturer, $\mathrm{Fe}^{0}$ content, average particle size and surface area were

$14965 \sim 80 \%, 50 \mathrm{~nm}$, and 25 30 $\mathrm{m}^{2} \mathrm{~g}^{-1}$, respectively. Entrapped nZVI beads were prepared according to

150 the methods described in detail elsewhere (Babuponnusami and Muthukumar, 2013; Bezbaruah et

151 al., 2014; Sun et al., 2017). Briefly, as shown in Fig. S1, $2.0 \mathrm{~g}$ of Na-alginate were dissolved in 100

152 mL DIW completely, and then were left to allow air bubbles to outflow (Solution 1). After that, 1.0 
$153 \mathrm{~g} \mathrm{nZVI}$ was gently added to Solution 1 and continuously stirred with a glass rod (Solution 2). Then,

154 the mixture was rapidly added drop-wise into $4.64 \% \mathrm{w} / \mathrm{v} \mathrm{CaCl}_{2}$ (Solution 3) by means of a 155 peristaltic pump (Baoding Longer Precision Pump Co., Ltd. $0.5 \mathrm{~mm}$ ID tubing, $2.5 \mathrm{~mL} \mathrm{~min}^{-1}$ flow 156 rate) from a height of $12 \mathrm{~cm}$ above the water surface to form alginate entrapped nZVI. The beads

157 were retained in Solution 3 for 6-9 $\mathrm{h}$ to achieve adequate hardness and porosity, and then washed 158 and stored in DIW.

160 For PVA-alginate entrapped nZVI, a 10\% w/v Na-alginate solution was prepared by dissolving $5 \mathrm{~g}$

161 Na-alginate in $50 \mathrm{~mL}$ DIW. Then, $3 \mathrm{~g}$ PVA was added to $40 \mathrm{~mL}$ DIW and stirred at $80^{\circ} \mathrm{C}$ until 162 complete dissolution. Then, $10 \mathrm{~mL}$ of $10 \% \mathrm{w} / \mathrm{v}$ Na-alginate solution was added into PVA solution 163 and stirred for $45 \mathrm{~min}$. One gram nZVI was added to the mixture after the temperature decreased to $16435^{\circ} \mathrm{C}$. The remaining steps to obtain PVA-alginate entrapped nZVI were the same as those for 165 alginate entrapped nZVI. Blank alginate and PVA-alginate beads without nZVI were also prepared

166 for comparison using the same procedures for the entrapped nZVI beads except the addition of 167 nZVI.

169 Characteristics of the synthesized entrapped nZVI have been measured and presented in our 170 previous study (Sun et al., 2017). In summary, the entrapped nZVI beads had a spherical shape and 171 the average diameter of PVA-alginate entrapped nZVI (4 beads $\approx 2 \mathrm{~cm})$ was slightly larger than 172 alginate entrapped nZVI ( 4 beads $\approx 1.5 \mathrm{~cm}$ ) (Fig. S2). In terms of comparative Fe content, the Fe 173 amount in each PVA-alginate entrapped nZVI $\left(1.14 \mu \mathrm{g} \mathrm{bead}^{-1}\right)$ was about two times that in alginate 174 entrapped nZVI $\left(0.53 \mu \mathrm{g} \mathrm{bead}^{-1}\right)$. 
$1762.4 \mathrm{CT}$ and 1,1,2-TCA removal by bare and entrapped nZVI in fracturing wastewater

177 In order to investigate the degradation kinetics of CT and 1,1,2-TCA by bare nZVI, $1.0 \mathrm{~g} \mathrm{~L}^{-1} \mathrm{nZVI}$

178 was used to treat $2 \mathrm{mg} \mathrm{L}^{-1} \mathrm{CT}$ or $1,1,2-\mathrm{TCA}$ in $60-\mathrm{mL}$ glass vials with triple sealed closures

179 containing 50-mL of Day-1, Day-14, or Day-90 FWW. The reaction was initiated by mixing nZVI

180 and FWW in the glass vials. Then, the vials were rapidly capped and placed in an end-over-end

181 rotary shaker $(30 \mathrm{rpm})$ at room temperature for $5,10,15,30,60,90,120$, and $240 \mathrm{~min}$. All the

182 samples were tested in duplicate and control tests without nZVI were also included to evaluate the

183 loss of target compounds due to sorption and volatilization. In addition, a batch experiment

184 involving the replacement of FWW by DIW (i.e., CT/1,1,2-TCA, nZVI and DIW only) was also

185 carried out to investigate the effects of the fracturing wastewater chemistry. At a specified reaction

186 time, the samples were centrifuged at 4,000 rpm for $5 \mathrm{~min}$ and $1 \mathrm{~mL}$ of supernatant was mixed with

$1872 \mathrm{~mL}$ hexane thoroughly by vortexing for $3 \mathrm{~min}$ to extract the target compound (Danish et al., 2016:

$188 \mathrm{Wu}$ et al., 2014). After 5-min standing, the organic phase (target compound in hexane) was

189 transferred to a $2 \mathrm{~mL}$ gas chromatograph (GC) vial with a glass syringe. The GC vials were sealed

190 with parafilm and stored at $4^{\circ} \mathrm{C}$ before analysis. The recovery of the organics via the extraction

191 procedure was in the range of $85-95 \%$.

192

193 To investigate organic removal by entrapped nZVI in Day-90 wastewater, $1.0 \mathrm{~g} \mathrm{~L}^{-1} \mathrm{nZVI}$ was

194 replaced by 47 alginate entrapped beads or 22 PVA-alginate entrapped beads with 25 mL Day-90

195 FWW in 60-mL glass vials, based on a mass balance calculation. Control studies with FWW only

196 were conducted to evaluate the loss of organics during experiments. The removal of organics by 
alginate and PVA-alginate beads without nZVI were also performed in parallel to investigate the

198 effect of the polymer matrix on organic removal, in which the amount of alginate and PVA-alginate were the same as that used in organic removal by entrapped nZVI. All the experiments were carried out in duplicate.

\subsection{Chemical stability of entrapped nZVI}

Freshly made alginate or PVA-alginate entrapped nZVI beads containing $5 \mathrm{~g}$ nZVI were added in a bottle containing $300 \mathrm{~mL}$ of DIW, Day-1 or Day-90 model FWW. The bottles were placed at room temperature and shaken by hand for 5 min everyday. After aging for one month, the solid beads removal from Day-90 FWW as described above. In addition, the entrapped nZVI beads before and after aging were freeze-dried for characterization. The crystal phases were analyzed by high-resolution powered X-ray diffraction (XRD, Rigaku SmartLab, Japan). For the aqueous phase,

210 the total organic carbon (TOC) content, $\mathrm{Na}$ and Fe content were measured before and after the 211 1-month aging process by TOC analyzer (SSM-5000A, Shimadzu, Japan, limit of detection of 0.1 $212 \mathrm{mg} \mathrm{L}^{-1}$ ) and atomic adsorption spectrometer (AAS, Agilent VGA77, USA, limit of detection of 0.1 $213 \mathrm{mg} \mathrm{L}^{-1}$ ), respectively. To illustrate the extent of dissolution, TOC, $\mathrm{Na}$ and Fe content in freshly 214 made entrapped nZVI were calculated based on their compositions and mass balance (details in 215 Supplementary Information). Gas chromatography/mass spectrometry (GC-MS) was also used to 216 identify the dissolved organic contents following extraction with $2 \mathrm{~mL}$ of hexane as described in

\section{Section 2.6.}


220 GC-MS (Agilent 7890B GC analyzer, 5977 Mass Selective Detector, USA) was used to measure 221 concentrations of $\mathrm{CT}$ and 1,1,2-TCA subsequent to the hexane extraction procedure. A DB-5 MS 222 column (30 m long, and $0.25 \mu \mathrm{m}$ thick film with $0.25 \mathrm{~mm}$ internal diameter) from Agilent 223 Technologies was used, with helium as the carrier gas. The oven temperature was maintained at $22435^{\circ} \mathrm{C}$ for $4 \mathrm{~min}$, then increased at $10^{\circ} \mathrm{C}$ per min until $100^{\circ} \mathrm{C}$ was reached, and further increased at $22530^{\circ} \mathrm{C}$ per min to $190^{\circ} \mathrm{C}$. Samples were injected with a rate of $1 \mathrm{~mL} \mathrm{~min}^{-1}$ at $230^{\circ} \mathrm{C}$ and detected at $226280^{\circ} \mathrm{C}$. Selected ion monitoring was used to acquire results. Calibration of standard organic 227 concentrations including intermediates was carried out before the analysis of samples. Organic 228 standards of $0.5 \mathrm{mg} \mathrm{L}^{-1}$ were analyzed every 10 samples for quality assurance and quality control. 229 The concentrations of Fe dissolved from bare and entrapped nZVI during the batch experiments 230 were measured by the AAS (limit of detection of $0.1 \mathrm{mg} \mathrm{L}^{-1}$ ) after further digestion by $5 \% \mathrm{HNO}_{3}$.

\subsection{Statistical analysis}

233 All experiments were performed in duplicate and the results were presented as mean \pm standard 234 deviations. One-way ANOVA followed by the Duncan test was applied to analyze the significance 235 of the difference between two sets of data (SPSS version 22.0).

\section{Results and discussion}


the whole experimental period and under all the conditions (data not shown). In contrast, rapid CT

242 degradation was observed in the initial 60 min (Fig. 1a), and the degradation after 4-h reaction was

$24362.7 \pm 2.9 \%$ in DIW, $53.5 \pm 6.3 \%$ in Day-1 FWW, $50.4 \pm 4.6 \%$ in Day-14 FWW, and $38.7 \pm 1.4 \%$ in

244 Day-90 FWW, respectively. Similarly, marginal 1,1,2-TCA degradation was observed after 60-min

245 reaction (Fig. 1b), and the 4-h removal efficiency reached $94.1 \pm 2.8 \%$ in DIW, $71.1 \pm 1.1 \%$ in Day-1

246 FWW, 37.4 $\pm 0.6 \%$ in Day-14 FWW, and $21.7 \pm 1.7 \%$ in Day-90 FWW, respectively.

248 The removal kinetics for both $\mathrm{CT}$ and 1,1,2-TCA by bare nZVI agreed with the 249 pseudo-second-order kinetic model (Supplementary Information) and the resulting kinetic 250 parameters are shown in Table 1. Interestingly, for both CT and 1,1,2-TCA, bare nZVI presented the 251 greatest reactivity in DIW, while the highest calculated surface-area normalized rate constants $\left(k_{\mathrm{SA}}\right.$, $252 \mathrm{~L} \mathrm{~m}^{-2} \mathrm{~h}^{-1}$ ) (i.e., $1.39 \times 10^{-1} \mathrm{~L} \mathrm{~m}^{-2} \mathrm{~h}^{-1}$ for $\mathrm{CT}$ and $2.61 \times 10^{-1} \mathrm{~L} \mathrm{~m}^{-2} \mathrm{~h}^{-1}$ for $1,1,2-\mathrm{TCA}$ ) were both 253 observed in Day-1 FWW. This might be ascribed to the presence of moderate amount of $\mathrm{Cl}^{-}$in 254 Day-1 FWW (Table S1) that could enforce the breakdown of protective oxide film on nZVI surface 255 and render more $\mathrm{Fe}^{0}$ available for target contaminants (Sun et al., 2016). However, the effect was 256 relatively short-lived and nZVI was probably re-oxidized leading to the formation of a new passive 257 oxide film (Liu et al., 2007; Reinsch et al., 2009; Xie and Cwiertny, 2012), thereby inhibiting the 258 reactivity with subsequent exposure or at higher concentration of $\mathrm{Cl}^{-}$.

260 The results indicate that the performance of bare nZVI on CT and 1,1,2-TCA reduction was 261 significantly affected by ionic strength $(I)$, as indicated by the order of decreasing 4-h degradation 262 efficiency: DIW $(I=0 \mathrm{M})>\operatorname{Day}-1(I=0.35 \mathrm{M})>\operatorname{Day}-14(I=2.49 \mathrm{M})>\operatorname{Day}-90(I=4.10 \mathrm{M})($ Figs. 
$1 \mathrm{~A} \& \mathrm{~B})$. It is well recognized that increasing ionic strength compresses the electrical double layer

264 on nZVI surfaces and alleviates the repulsive forces, thus enhancing particle aggregation that results

265 in fewer accessible reactive sites and limited nZVI reactivity for organic degradation (Garner and

266 Keller, 2014). The presence of $\mathrm{NO}_{3}^{-}(1.04 \mathrm{mM}$ in Day-1, $4.01 \mathrm{mM}$ in Day-14, and $6.27 \mathrm{mM}$ in

267 Day-90) in FWW could be partially responsible for the lower reactivity of bare nZVI in FWW

268 compared to that in DIW. In addition to surface passivation, $\mathrm{NO}_{3}{ }^{-}$, as an iron reducible anion, can

269 compete with target contaminants for the reactive sites on nZVI surface (Sun et al., 2016), and the

270 extent of the inhibition would increase with increasing $\mathrm{NO}_{3}{ }^{-}$concentration $(>1 \mathrm{mM})($ Liu et al.,

271 2007). Hence, the reactivity of bare nZVI towards CT and 1,1,2-TCA degradation in FWW was

272 clearly lower as a result of the nature of FWW water chemistry.

273

274 Due to aqueous corrosion of nZVI, continuous Fe dissolution was observed during CT and

275 1,1,2-TCA removal by bare nZVI in DIW and FWWs (Fig. 1c). The extent of Fe dissolution was

276 independent of the organic species but largely dependent on the ionic strength. After 4-h reaction,

277 only $0.57 \pm 0.08 \%$ Fe was dissolved into DIW while much greater Fe dissolution corresponded to

278 increasing $I$ in Day-1 $(I=0.35 \mathrm{M}, 1.31 \pm 0.09 \%)$, Day-14 $(I=2.49 \mathrm{M}, 3.82 \pm 0.13 \%)$, and Day-90

279 FWW $(I=4.10 \mathrm{M}, 5.79 \pm 0.32 \%)$. The increase in $I$ could provide stronger separation between

280 anodic and cathodic regions and allow the corrosion products (e.g., $\mathrm{Fe}^{2+}$ ) to diffuse from the nZVI

281 surface and enter the solution, which may even reverse surface passivation and lead to surface

282 dissolution (Farrell et al., 2000). However, considering potential toxicity of iron in the environment

283 (Lei et al., 2016; Lei et al., 2018), a high Fe concentration in FWW after nZVI treatment may

284 require toxicity assessment and proper nZVI modification to suppress Fe dissolution in FWW. 
$2863.2 \mathrm{CT}$ and 1,1,2-TCA removal by entrapped nZVI in fracturing wastewater

287 Alginate entrapped nZVI was firstly introduced to Day-90 FWW, in which bare nZVI exhibited the 288 poorest performance in CT and 1,1,2-TCA degradation. After 4-h reaction, alginate entrapped nZVI 289 presented a comparable CT removal efficiency with bare nZVI $(p=0.214)$ (Fig. S3). Similar results 290 were reported for TCE, nitrate, and arsenic removal (Bezbaruah et al., 2009; Bezbaruah et al., 2011; 291 Bezbaruah et al., 2014). However, the rate constant $k_{\mathrm{SA}}\left(2.36 \times 10^{-1} \mathrm{~L} \mathrm{~m}^{-2} \mathrm{~h}^{-1}\right)$ for alginate entrapped 292 nZVI was one order-of-magnitude greater than for bare nZVI $\left(3.71 \times 10^{-2} \mathrm{~L} \mathrm{~m}^{-2} \mathrm{~h}^{-1}\right)$ (Table 1). This 293 could be attributed to the affinity of organics to alginate, which in turn enhanced the contact 294 between CT and nZVI (Kuang et al., 2015). No significant increase in the reactivity of nZVI toward 295 CT removal was observed after the entrapment, thus further addition of PVA in the polymer matrix 296 was not conducted.

298 For 1,1,2-TCA removal, alginate entrapped nZVI not only produced a higher rate constant $k_{\mathrm{SA}}$ $299\left(2.40 \times 10^{-1} \mathrm{~L} \mathrm{~m}^{-2} \mathrm{~h}^{-1}\right)($ Table 1), but also showed a superior performance in 1,1,2-TCA removal (Fig. 2a) compared with the bare nZVI. A pronounced decrease in 1,1,2-TCA concentration was observed in the first $60 \mathrm{~min}$ and the removal efficiency reached $62.6 \pm 1.7 \%$ after 4 -h reaction with alginate entrapped nZVI. It was evident that pure alginate beads (no nZVI) could absorb 1,1,2-TCA to some extent and contributed to the removal of $18.2 \pm 6.0 \% 1,1,2-\mathrm{TCA}$ within $4 \mathrm{~h}$ (Fig. 2a). Previous

304 studies ascribed similar observation to physical sorption onto alginate beads, while the reduction 305 was limited (Bezbaruah et al., 2011; Bezbaruah et al., 2014). In this study, the extremely high salt 
exclude 1,1,2-TCA from the wastewater and thereby enhance the partitioning/penetration of the

308 compound into the beads (Wang et al., 2010).

309

310 There appeared to be a synergistic effect between the alginate polymer matrix and the immobilized

311 nZVI leading to the much greater 1,1,2-TCA removal (Fig. 2a). On one hand, the porous nature of

312 the alginate allows the diffusion of the compound within the beads and thus contact with

313 immobilized nZVI (Bezbaruah et al., 2014). As the immobilized nZVI particles are restrained

314 within the confined space of the beads without significant modification of the surface, there is little

315 compromise of their reactivity for contaminant reduction, as reported in DIW or background

316 solutions with low I (Bezbaruah et al., 2009; Bezbaruah et al., 2011). On the other hand, due to the

317 increased affinity of 1,1,2-TCA to the alginate polymer matrix, the adsorbed molecules are more

318 available for the reduction by the immobilized nZVI (Kuang et al., 2015). The alginate polymer

319 matrix could also serve as a physical barrier to the aggregation of entrapped nZVI, thereby

320 providing more accessible reactive sites for reaction (Cho et al., 2015; Lee et al., 2016). These

321 reasons possibly account for the superior performance of alginate entrapped nZVI in 1,1,2-TCA

322 removal from Day-90 FWW compared to bare nZVI.

324 Introduction of PVA as a co-polymer for the entrapment further improved 1,1,2-TCA removal

325 efficiency (72.8 $\pm 3.6 \%$ ) after 4-h reaction compared to alginate entrapped nZVI (Fig. 2a). However,

326 a smaller rate constant $k_{\mathrm{SA}}\left(9.37 \times 10^{-2} \mathrm{~L} \mathrm{~m}^{-2} \mathrm{~h}^{-1}\right)$ was recorded (Table 1$)$, which probably reflected

327 the increased mass transfer limitation in the denser polymeric matrix enclosing nZVI after PVA

328 addition ( $\mathrm{Lv}$ et al., 2013). It was also found that 1,1,2-TCA was significantly removed by 
adsorption onto PVA-alginate beads (without nZVI) after 30-min $(45.3 \pm 4.6 \%)$ and 4-h reaction $(60.2 \pm 1.8 \%)$ (Fig. 2a). The outstanding adsorption capacity of PVA-alginate beads was not anticipated, which might be due to specific bonding between PVA and 1,1,2-TCA that requires further investigation.

\section{These results indicated that 1,1,2-TCA adsorption by the PVA-alginate polymer matrix was the} primary removal mechanism for PVA-alginate entrapped nZVI beads. The difference between the total removal and the adsorption removal by the PVA-alginate entrapped nZVI suggested that at least $12.6 \%$ of $1,1,2-\mathrm{TCA}$ was removed by the nZVI reduction. However, the contribution of chemical reduction was rather limited, possibly because substantial adsorption onto the matrix reduced the accessibility and subsequent reduction on the nZVI surface, which was similarly observed with polyelectrolyte coating (Phenrat et al., 2009) and powdered activated carbon-alginate matrix (Kim et al., 2010).

Therefore, in this study, the proposed mechanisms for 1,1,2-TCA removal by entrapped nZVI consisted of adsorption by the polymer matrix and chemical reduction by the immobilized nZVI. Kuang et al. (2015) suggested that the simultaneous removal of $\mathrm{Cu}$ and monochlorobenzene by alginate entrapped Ni-doped nZVI beads was a two-step process involving competitive adsorption and catalytic reduction. Similarly, oleic acid-coated alginate entrapped Pd-doped nZVI beads were reported to remove trichlorophenol in water via fast sorption by the polymer layer followed by subsequent dechlorination (Chang et al., 2015). Our results suggested that the adsorption capacity of polymer matrix (i.e., low in alginate but high in PVA-alginate) played a crucial role in 
determining the relative significance of chemical reduction by the immobilized nZVI (i.e., high in alginate but low in PVA-alginate).

353

Besides, owing to the protective effect of the polymer matrix, much less Fe was released into the 355 solution during 1,1,2-TCA removal by alginate entrapped nZVI (4.69 $\pm 0.30 \%)$ and PVA-alginate entrapped nZVI $(4.00 \pm 0.19 \%)$ (Fig. 2b) than with bare nZVI $(5.79 \pm 0.32 \%)$ (Fig. 1c). The polymer matrix was reported to adsorb metal ions via the carboxyl groups in alginate and hydroxyl groups in PVA (Lim et al., 2008; Bai et al., 2009; Wang and Wang, 2016), which was possibly responsible for the reduced release of aqueous Fe. Our previous work also demonstrated that nZVI entrapment could improve metal/metalloid (i.e., $\mathrm{Zn}, \mathrm{Cr}$, and As) removal from $\mathrm{FWW}$ and alleviate $\mathrm{Fe}$ dissolution (Sun et al., 2017). Hence, the high reactivity, easy recovery, and low Fe dissolution of 362 entrapped nZVI make it a good candidate for high-salinity FWW treatment. The durability and long-term effectiveness of entrapped nZVI were investigated in the following section.

3.3 Long-term durability and stability of entrapped nZVI

Dissolution levels of different components of entrapped nZVI after 1-month aging in DIW, Day-1 and Day-90 FWW are presented in Table 2. TOC dissolution was only detected for the PVA-alginate entrapped nZVI, and a higher $I$ in FWW caused greater TOC dissolution. After 1-month aging, $2.09 \%$ of the initial TOC content in PVA-alginate entrapped nZVI was dissolved into DIW while the TOC dissolution dramatically increased to $10.1 \%$ and $17.5 \%$ for PVA-alginate entrapped nZVI aged in Day-1 and Day-90 FWW, respectively. Lv et al. (2013) also reported a high 
first run, although the TOC release decreased sharply in the second and third runs.

The TOC release was associated with the decrease in the diameter of the PVA-alginate beads from initially $2.0 \mathrm{~cm}$ to $1.7 \mathrm{~cm}$ of 4 beads after 1-month aging in Day-1/Day-90 FWW (Fig. S2). GC-MS analysis revealed the existence of compounds with $\mathrm{C}=\mathrm{O}$ group in the solution samples after aging of PVA-alginate entrapped nZVI. This functional group was only found in alginate, implying the dissolution of alginate during the aging process. Both alginate and PVA could form hydrogen bonds with the immobilized nZVI, and strong hydrogen bonding also existed between alginate and PVA (Zain et al., 2011; Lv et al., 2013; Huang et al., 2016). The addition of PVA seemed to outcompete and destabilize the hydrogen bonding between alginate and nZVI, thereby resulting in the release of alginate. The dissolution of water-soluble PVA could not be ruled out during the aging process. Hence, physical (e.g., freeze-thawing) or chemical (e.g., boric acid or sodium sulphate) cross-linking should be conducted on PVA to make it insoluble (Nunes et al., 2010; Zain et al., 2011; Wang and Wang, 2016) before application in future studies. Besides, leakage of $\mathrm{Na}$ from entrapped nZVI after 1-month aging increased with increasing I from Day-1 to Day-90 FWW (Table 2), which was primarily attributed to the ion-exchange reaction with residual $\mathrm{Na}$ on alginate (Lim et al., 2008; Huang et al., 2016), despite calcium chloride hardening before usage in this study.

Owing to the effective protection from the polymer matrix, there was negligible Fe dissolution after 1-month aging, where only at most $0.026 \%$ of the Fe content in the beads leached in Day-90 FWW (Table 2), which could be related to the presence of a few injured/broken beads (Fig. S2). Similar XRD patterns were obtained for both alginate and PVA-alginate entrapped nZVI before and after 
the aging process (Fig. 3). In all the samples, only the typical peaks for $\mathrm{Fe}^{0}$ at $2 \theta$ of about $45^{\circ}$ and

$39665^{\circ}$ were detected, indicating no formation of any new crystalline phase during the 1-month aging.

397 In contrast, Reinsch et al. (2010) demonstrated that aging of nZVI in anaerobic DIW alone or in the

398 presence of common groundwater anions $\left(\mathrm{Cl}^{-}, \mathrm{NO}_{3}^{-}, \mathrm{SO}_{4}{ }^{2-}, \mathrm{HPO}_{4}{ }^{2-}\right.$, and $\left.\mathrm{HCO}_{3}{ }^{-}\right)$for 1 month

399 resulted in the oxidation of $\mathrm{Fe}^{0}$ to $\mathrm{Fe}_{3} \mathrm{O}_{4}$. Liu et al. (2015) even reported the formation of

$400 \mathrm{Fe}_{3} \mathrm{O}_{4} / \gamma-\mathrm{Fe}_{2} \mathrm{O}_{3}$ and $\gamma$-FeOOH after 5-day exposure of nZVI to static water.

In this study, Fig. 3 revealed that the immobilized nZVI remained $\mathrm{Fe}^{0}$ state and/or amorphous iron

nZVI from the polymer matrix against oxidation. Luo et al. (2014) also reported that the

immobilization of nZVI in alginate microcapsules alleviated the susceptibility of nZVI to oxidation

in the environment. Hence, the entrapment of nZVI in a polymer matrix could not only restrain $\mathrm{Fe}$ dissolution but also mitigate nZVI aging process in the aqueous environment.

Fig. 4 presents the reactivity of entrapped nZVI in terms of 1,1,2-TCA removal in Day-90 FWW before and after 1-month aging. The aging of entrapped nZVI substantially decreased its capacity for 1,1,2-TCA removal, except for alginate entrapped nZVI aged in DIW. A few studies documented that nZVI would gradually lose their reactivity with the progress of aging, especially for organics removal, as a result of the reduced $\mathrm{Fe}^{0}$ content and/or a thickening surface iron oxide layer (Xie and

414 Cwiertny, 2012; Pullin et al., 2017). In this study, on one hand, the oxidation of the immobilized 415 nZVI into amorphous iron oxides was possible during the 1-month aging process, which would 416 decrease $\mathrm{Fe}^{0}$ content and suppress the performance of aged entrapped nZVI. On the other hand, 
417 FWW contained a high concentration of salts, which might be adsorbed by the polymer matrix and

418 thereby blocking the pores for contaminant diffusion. Certain amount of salts may even be able to

419 pass through the polymer matrix and attach to the surface of the immobilized nZVI, resulting in less

420 accessible reactive sites for organic reduction (Hwang et al., 2015).

422 With respect to PVA-alginate entrapped nZVI, the primary cause might be the dissolution of the 423 polymer matrix, considering its pronounced contribution of adsorption to the overall 1,1,2-TCA 424 removal. The released polymer debris might in turn result in pore clogging and mass transfer 425 limitation. Although the 1-month aging notably inhibited their reactivity, entrapped nZVI particles 426 still showed comparable efficiency for 1,1,2-TCA removal by bare nZVI in Day-90 FWW. These 427 results reinforced the application potential of entrapped nZVI, yet more research is still needed to 428 improve the long-term chemical stability of the polymer matrix for nZVI immobilization.

\subsection{Economic viability}

431 As shown in this study, entrapped nZVI is a promising material for high-salinity FWW wastewater 432 treatment, while it can also be applied in permeable reactive barriers for simultaneous removal of 433 metals and organics from groundwater wastewater (Kuang et al., 2015) and deployed as packing 434 materials in a fixed-bed process with continuous-flow wastewater treatment (Chang et al., 2015). To 435 illustrate the economic feasibility of entrapped nZVI for wastewater treatment, a preliminary cost 436 analysis was performed in the present study. 
stirring and dripping systems in the industrial scale. According to the online quotations from the largest regional supplier (Alibaba.com China, https://www.1688.com), the prices of sodium alginate, PVA, and $\mathrm{CaCl}_{2}$ are approximately $\$ 5 \mathrm{~kg}^{-1}, \$ 1.5 \mathrm{~kg}^{-1}$, and $\$ 0.1 \mathrm{~kg}^{-1}$, respectively. The price for nZVI varied between $£ 50$ and $£ 150$ per $\mathrm{kg}$ (Crane and Scott, 2012), and a median price $£ 100 \mathrm{~kg}^{-1}$ was chosen for cost analysis in this study. To simplify the scenario, fixed and variable costs for equipment, labour, maintenance etc., are supposed to be available on site. The total costs of entrapped nZVI were \$154.8 per kg nZVI for alginate entrapped nZVI and \$158.7 per kg nZVI for PVA-alginate entrapped nZVI, respectively (calculation details are available in Supplementary Information). Thus, the treatment costs are estimated to about $\$ 154.8 \mathrm{~m}^{-3}$ and $\$ 158.7 \mathrm{~m}^{-3}$ for FWW pretreatment with $1 \mathrm{~g} \mathrm{~L}^{-1} \mathrm{nZVI}$. Adeleye et al. (2016) reported that the costs of current technologies for wastewater treatment ranges from $\$ 90 \mathrm{~m}^{-3}$ per day to $\$ 2800 \mathrm{~m}^{-3}$ per day. Hence, the application of entrapped nZVI is financially viable for FWW treatment, and it will be even more competitive if the price of nZVI can be reduced by future technological advances.

\section{Conclusions}

This study investigated the potential application of nZVI for the removal of chlorinated organic solvents from high-salinity FWW. Bare nZVI was sensitive to FWW composition and suffered from substantial Fe dissolution and reduction in CT and 1,1,2-TCA degradation efficiency with increasing ionic strength in FWW. The decreased reactivity of nZVI was due to the combined effect of the complex water chemistry of FWW, and primarily attributed to its high ionic strength which induced particle aggregation. The effective immobilization of nZVI in alginate or PVA-alginate polymer matrix prevented particle aggregation and achieved superior performance for 1,1,2-TCA 
removal, associated with less Fe dissolution. Entrapped nZVI could remove 1,1,2-TCA via both

adsorption (by the polymer matrix) and chemical reduction (by the immobilized nZVI). Chemical reduction was the dominant removal mechanism observed in alginate entrapped nZVI while adsorption was the primary mechanism in PVA-alginate entrapped nZVI. With the protection of the polymer matrix, the oxidation of the immobilized nZVI was moderate without forming new crystalline phase during 1-month aging in fracturing wastewater. The aging process significantly inhibited the reactivity of entrapped nZVI for 1,1,2-TCA removal, but was however still comparable to the performance of bare nZVI in Day-90 FWW. Hence, entrapped nZVI overcame potential interference from the constituents of FWW and demonstrated practical advantages of high reactivity, economical production, easy storage, and environmental benignity for the treatment of high-salinity fracturing wastewaters.

472

\section{Acknowledgement}

474 The authors appreciate the financial support from the National Natural Science Foundation of China 475 (21407121, 21525728), National Key Research and Development Program of China 476 (2017YFA0207003), Hong Kong Research Grants Council (PolyU 15222115 and 15223517), and 477 State Key Laboratory of Urban Water Resource and Environment of Harbin Institute of Technology 478 (HCK201309) for this study.

\section{References}

481 Abualfaraj, N., Gurian, P. L., Olson, M. S., 2014. Characterization of Marcellus shale flowback water. Environ. Eng. Sci. 31, 514-524. 
Adeleye, A. S., Conway, J. R., Garner, K., Huang, Y., Su, Y., Keller, A. A., 2016. Engineered nanomaterials for water treatment and remediation: Costs, benefits, and applicability. Chem. Eng. J. 286, 640-662.

Babuponnusami, A., and Muthukumar, K., 2013. Treatment of phenol-containing wastewater by photoelectro-Fenton method using supported nanoscale zero-valent iron. Environ. Sci. Pollut. R. 20, 1596-1605.

Bai, X., Ye, Z. F., Qu, Y.Z., Li, Y.F., Wang, Z.Y., 2009. Immobilization of nanoscale $\mathrm{Fe}^{0}$ in and on PVA microspheres for nitrobenzene reduction. J. Hazard. Mater. 172, 1357-1364.

Bezbaruah, A. N., Kalita, H., Almeelbi, T., Capecchi, C. L., Jacob, D. L., Ugrinov, A. G., Payne, S. A., 2014. Ca-alginate-entrapped nanoscale iron: arsenic treatability and mechanism studies. J. Nanopart. Res. 16, 1-10.

Bezbaruah, A. N., Krajangpan, S., Chisholm, B. J., Khan, E., Bermudez, J. J. E., 2009. Entrapment of iron nanoparticles in calcium alginate beads for groundwater remediation applications. J. Hazard. Mater. 166, 1339-1343.

Bezbaruah, A. N., Shanbhogue, S. S., Simsek, S., Khan, E., 2011. Encapsulation of iron nanoparticles in alginate biopolymer for trichloroethylene remediation. J. Nanopart. Res. 13, 6673-6681.

Blewett, T. A., Delompré, P. L. M., He, Y., Folkerts, E. J., Flynn, S. L., Alessi, D. S., Goss, G. G., 2017. Sublethal and reproductive effects of acute and chronic exposure to flowback and produced water from hydraulic fracturing on the water flea daphnia magna. Environ. Sci. Technol. 51, 3032-3039.

Chang, J., Woo, H., Ko, M-S., Lee, J., Lee, S., Yun, S-T., Lee, S., 2015. Targeted removal of 
trichlorophenol in water by oleic acid-coated nanoscale palladium/zero-valent iron alginate beads. J. Hazard. Mater. 293, 30-36.

Chen, S.S., Sun, Y., Tsang, D.C.W., Graham, N.J.D., Ok, Y.S., Feng, Y., Li, X.D., 2016. Potential impact of flowback water from hydraulic fracturing on agricultural soil quality: metal/metalloid bioaccessibility, Microtox bioassay, and enzyme activities. Sci. Total Environ. $579,1419-1426$.

Chen, S.S., Sun, Y., Tsang, D.C.W., Graham, N.J.D., Ok, Y.S., Feng, Y., Li, X.D., 2017. Insights into the subsurface transport of $\mathrm{As}(\mathrm{V})$ and $\mathrm{Se}(\mathrm{VI})$ in produced water from hydraulic fracturing using soil samples from Qingshankou Formation, Songliao Basin, China. Environ. Pollut. 223, 449-456.

Cho, D. W., Song, H., Kim, B., Schwartz, F. W., Jeon, B. H., 2015. Reduction of nitrate in groundwater by $\mathrm{Fe}(0) /$ Magnetite nanoparticles entrapped in Ca-Alginate beads. Water. Air.

Estrada, J. M., Bhamidimarri, R., 2016. A review of the issues and treatment options for wastewater

Danish, M., Gu, X. G., Lu, S. G., Naqvi, M., 2016. Degradation of chlorinated organic solvents in aqueous percarbonate systemusing zeolite supported nano zero valent iron (Z-nZVI) composite. Environ. Sci. Pollut. Res. 23, 13298-13307.

Farrell, J., Kason, M., Melitas, N., Li, T., 2000. Investigation of the long-term performance of 
528

Garner, K. L. and Keller, A. A., 2014. Emerging patterns for engineered nanomaterials in the environment: a review of fate and toxicity studies. J. Nanopart. Res. 16, 1-28.

Gregory, K. B., Vidic, R. D., Dzombak, D. A., 2011. Water management challenges associated with the production of shale gas by hydraulic fracturing. Elements. 7, 181-186.

Hayes, T., December 31, 2009. Sampling and analysis of water streams associated with the development of marcellus shale gas. Final report prepared for the Marcellus Shale Coalition.

He, Y., Folkerts, E. J., Zhang, Y., Martin, J. W., Alessi, D. S., Goss, G. G., 2017. Effects on biotransformation, oxidative stress, and endocrine disruption in rainbow trout (Oncorhynchus mykiss) exposed to hydraulic fracturing flowback and produced Water. Environ. Sci. Technol. $51,940-947$.

Huang, J. F., Li, Y. T., Wu, J. H., Cao, P. Y., Liu, Y. L., Jiang, G. B., 2016. Floatable, macroporous structured alginate sphere supporting iron nanoparticles used for emergent $\mathrm{Cr}(\mathrm{VI})$ spill treatment. Carbohydr Polym. 146, 115-122.

Hwang, Y., Kim, D., Shin,. H. S., 2015. Inhibition of nitrate reduction by $\mathrm{NaCl}$ adsorption on a nano-zero-valent iron surface during a concentrate treatment for water reuse. Environ. Technol. $36,1178-1187$.

Jagadevan, S., Jayamurthy, M., Dobson, P., Thompson, I. P., 2012. A novel hybrid nano zerovalent iron initiated oxidation-Biological degradation approach for remediation of recalcitrant waste metalworking fluids. Water Res. 46, 2395-2404.

Kim, H., Hong, H. J., Jung, J., Kim, S. H., Yang, J. W., 2010. Degradation of trichloroethylene (TCE) by nanoscale zero-valent iron (nZVI) immobilized in alginate bead. J. Hazard. Mater. 
176, 1038-1043.

550 Kuang, Y., Du, J., Zhou, R., Chen, Z., Megharaj, M., Naidu, R., 2015. Calcium alginate 551 monochlorobenzene, J. Colloid. Interface. Sci. 447, 85-91

Lee, C. S., Gong, J., Huong, C. V., Oh, D. S., Chang, Y. S., 2016. Macroporous alginate substrate-bound growth of $\mathrm{Fe}^{0}$ nanoparticles with high redox activities for nitrate removal from aqueous solutions. Chem. Eng. J. 298, 206-213.

Lei, C., Zhang, L., Yang, K., Zhu, L., Lin, D., 2016. Toxicity of iron-based nanoparticles to green algae: Effects of particle size, crystal phase, oxidation state and environmental aging. Environ Pollut. 218, 505-512.

Lei, C., Sun, Y., Tsang, D.C.W., Lin, D., 2018. Environmental transformations and ecological effects of iron-based nanoparticles. Environ. Pollut. 232, 10-30.

Lim, S. F., Zheng, Y. M., Zou, S. W., Chen, J. P., 2008. Characterization of copper adsorption onto an alginate encapsulated magnetic sorbent by a combined FT-IR, XPS, and mathematical Modeling Study. Environ. Sci. Technol. 42, 2551-2556.

Liu, A., Liu, J., Zhang, W. X., 2015. Transformation and composition evolution of nanoscale zero valent iron (nZVI) synthesized by borohydride reduction in static water. Chemosphere 119, 1068-1074.

Liu, T., Tsang, D. C., Lo, I. M., 2008. Chromium (VI) reduction kinetics by zero-valent iron in moderately hard water with humic acid: iron dissolution and humic acid adsorption. Environ. Sci. Technol. 42, 2092-2098.

Liu, Y., Phenrat, T., Lowry, G. V., 2007. Effect of TCE concentration and dissolved groundwater 
solutes on NZVI-promoted TCE dechlorination and H2 evolution. Environ. Sci. Technol. 41,

572

573

574

575

576

577

578

579

580

581

582

583

584

585

586

587

588

589

590

591

592
7881-7887.

Luo, S., Lu, T., Peng, L., Shao, J., Zeng, Q., Gu, J. D., 2014. Synthesis of nanoscale zero-valent iron immobilized in alginate microcapsules for removal of $\mathrm{Pb}(\mathrm{II})$ from aqueous solution, J. Mater. Chem. A. 2, 15463.

Lutz, B. D., Lewis, A. N., Doyle, M. W., 2013. Generation, transport, and disposal of wastewater associated with Marcellus Shale gas development. Water Resour. Res. 49, 647-656.

Lv, X., Jiang, G., Xue, X., Wu, D., Sheng, T., Sun, C., Xu, X., 2013. $\mathrm{Fe}^{0}-\mathrm{Fe}_{3} \mathrm{O}_{4}$ nanocomposites embedded polyvinyl alcohol/sodium alginate beads for chromium (VI) removal. J. Hazard. Mater. 262, 748-758.

Ma, L. and Zhang, W. X., 2008. Enhanced biological treatment of industrial wastewater with bimetallic zero-valent iron. Environ. Sci. Technol. 42, 5384-5389.

Nunes, M. A. P., Vila-Real, H., Fernandes, P. C. B., Ribeiro, M. H. L., 2009. Immobilization of naringinase in PVA-Alginate matrix using an innovative technique. Appl. Biochem. Biotechnol. 160, 2129-2147.

Phenrat, T., Liu, Y., Tilton, R. D., Lowry, G. V., 2009. Adsorbed polyelectrolyte coatings decrease $\mathrm{Fe}^{0}$ nanoparticle reactivity with TCE in water: conceptual model and mechanisms. Environ. Sci. Technol. 43, 1507-1514.

Pullin, H., Springell, R., Parry, S., Scott, T., 2016. The effect of aqueous corrosion on the structure and reactivity of zero-valent iron nanoparticles, Chem. Eng. J. 308, 568-577.

Reinsch, B. C., Forsberg, B., Penn, R. L., Kim, C. S., Lowry, G. V., 2010. Chemical transformations during aging of zerovalent iron nanoparticles in the presence of common groundwater 
594 Sharghi, E. A., Bonakdarpour, B., 2013. The study of organic removal efficiency and halophilic 595 bacterial mixed liquor characteristics in a membrane bioreactor treating hypersaline produced water at varying organic loading rates, Bioresour. Technol. 149, 486-495.

Silva, T. L. S., Morales-Torres, S., Castro-Silva, S., Figueiredo, J. L., Silva, A. M. T., 2017. An 598 overview on exploration and environmental impact of unconventional gas sources and treatment options for produced water. J. Environ. Manage. 200, 511-529.

Stefaniuk, M., Oleszczuk, P., Ok, Y. S., 2016. Review on nano zerovalent iron (nZVI): From synthesis to environmental applications. Chem. Eng. J. 287, 618-632.

Stringfellow, W. T., Domen, J. K., Camarillo, M. K., Sandelin, W. L., Borglin, S., 2014. Physical, 603 chemical, and biological characteristics of compounds used in hydraulic fracturing. J. Hazard. Mater. 275, 37-54.

Sun, Y., Lei, C., Khan, E., Chen, S. S., Tsang, D. C. W., Ok, Y. S., Lin, D. H., Feng, Y. J., Li, X. D., 606 2017. Nanoscale zero-valent iron for metal/metalloid removal from model hydraulic fracturing wastewater. Chemosphere, 176, 315-323.

Sun, Y., Li, J., Huang, T., Guan, X., 2016. The influences of iron characteristics, operating conditions and solution chemistry on contaminants removal by zero-valent iron: A review.

611 Wang, L.Y., Wang, M. J., 2016. Removal of heavy metal ions by poly(vinyl alcohol) and 612 carboxymethyl cellulose composite hydrogels prepared by a freeze-thaw method. ACS Sustain. Chem. Eng. 4, 2830-2837.

614 Wang, Y., Han, J., Xu, X. H., Hu, S. P., Yan, Y. S., 2010. Partition behavior and partition mechanism 
615 of antibiotics in ethanol/2-propanol-ammonium sulfate aqueous two-phase systems. Sep. Purif. $616 \quad$ Technol. $75,352-357$.

617 Xie, Y., Cwiertny, D. M., 2012. Influence of anionic cosolutes and $\mathrm{pH}$ on nanoscale zerovalent iron 618 longevity: time scales and mechanisms of reactivity loss toward 1,1,1,2-Tetrachloroethane and $619 \quad$ Cr(VI). Environ. Sci. Technol. 46, 8365-8373.

620 Wu, X. L., Lu, S. G., Qiu, Z. F., Sui, Q., Lin, K. F., Du, X. M., Luo, Q. S., 2014. The reductive 621 degradation of 1,1,1-trichloroethane by Fe(0) in a soil slurry system. Environ. Sci. Pollut. Res. $622 \quad 21,1401-1410$.

623 Yan, W., Lien, H. L., Koel, B. E., Zhang, W. X., 2013. Iron nanoparticles for environmental 624 clean-up: recent developments and future outlook. Environ. Sci: Process Impacts. 15, 63-77. 625 Yost, E. E., Stanek, J., DeWoskin, R. S., Burgoon, L. D., 2016. Overview of chronic oral toxicity 626 values for chemicals present in hydraulic fracturing fluids, flowback, and produced waters. 627 Environ. Sci. Technol. 50, 4788-4797.

628 Zain, N. A. M., Suhaimi, M. S., Idris, A., 2011. Development and modification of PVA-alginate as 629 a suitable immobilization matrix. Process Biochem. 46, 2122-2129. 
Table 1. Pseudo-second-order kinetics of CT and 1,1,2-TCA degradation in DIW, Day-1,

Day-14, Day-90 fracturing wastewater (FWW) by nZVI and entrapped nZVI

\begin{tabular}{|c|c|c|c|c|c|c|c|}
\hline Organic & nZVI type & Solution & $\begin{array}{c}q_{\mathrm{e} 2} \\
\left(\mathrm{~g} \mathrm{~kg}^{-1}\right)\end{array}$ & $\begin{array}{c}k_{2} \\
\left(\min ^{-1} \mathrm{~kg} \mathrm{~g}^{-1}\right)\end{array}$ & $\begin{array}{c}k_{2} q_{\mathrm{e} 2} \\
\left(\min ^{-1}\right)\end{array}$ & $\begin{array}{c}k_{\mathrm{sa}} \\
\left(\mathrm{L} \mathrm{m}^{-2} \mathrm{~h}^{-1}\right)\end{array}$ & $\mathrm{R}_{2}^{2}$ \\
\hline \multirow{5}{*}{ CT } & \multirow{4}{*}{ Bare nZVI } & DIW & 1.48 & $1.76 \times 10^{-2}$ & $2.60 \times 10^{-2}$ & $8.04 \times 10^{-2}$ & 0.993 \\
\hline & & Day-1 FWW & 1.16 & $3.88 \times 10^{-2}$ & $4.40 \times 10^{-2}$ & $1.39 \times 10^{-1}$ & 0.997 \\
\hline & & Day-14 FWW & 1.29 & $1.45 \times 10^{-2}$ & $1.86 \times 10^{-2}$ & $5.75 \times 10^{-2}$ & 0.970 \\
\hline & & Day-90 FWW & 1.05 & $1.14 \times 10^{-2}$ & $1.20 \times 10^{-2}$ & $3.71 \times 10^{-2}$ & 0.980 \\
\hline & $\begin{array}{c}\text { Alginate } \\
\text { entrapped nZVI }\end{array}$ & Day-90 FWW & 0.90 & $8.46 \times 10^{-2}$ & $7.64 \times 10^{-2}$ & $2.36 \times 10^{-1}$ & 0.980 \\
\hline \multirow{6}{*}{$1,1,2-\mathrm{TCA}$} & \multirow{4}{*}{ Bare nZVI } & $\overline{\text { DIW }}$ & 2.23 & $1.35 \times 10^{-2}$ & $3.00 \times 10-2$ & $9.28 \times 10^{-2}$ & 0.970 \\
\hline & & Day-1 FWW & 1.53 & $5.51 \times 10^{-2}$ & $8.44 \times 10^{-2}$ & $2.61 \times 10^{-1}$ & 0.996 \\
\hline & & Day-14 FWW & 0.80 & $6.21 \times 10^{-2}$ & $4.99 \times 10^{-2}$ & $1.54 \times 10^{-1}$ & 0.999 \\
\hline & & Day-90 FWW & 0.46 & $1.24 \times 10^{-1}$ & $5.73 \times 10^{-2}$ & $1.77 \times 10^{-1}$ & 0.999 \\
\hline & $\begin{array}{c}\text { Alginate } \\
\text { entrapped nZVI }\end{array}$ & Day-90 FWW & 1.34 & $5.78 \times 10^{-2}$ & $7.75 \times 10^{-2}$ & $2.40 \times 10^{-1}$ & 0.996 \\
\hline & $\begin{array}{c}\text { PVA-alginate } \\
\text { entrapped nZVI }\end{array}$ & Day-90 FWW & 1.71 & $1.77 \times 10^{-2}$ & $3.03 \times 10^{-2}$ & $9.37 \times 10^{-2}$ & 0.990 \\
\hline
\end{tabular}


Table 2. Dissolution from entrapped nZVI during 1-month aging.

\begin{tabular}{ccccc}
\hline nZVI type & Aging solution & $\begin{array}{c}\text { Na dissolution } \\
(\boldsymbol{\%})\end{array}$ & $\begin{array}{c}\text { Fe dissolution } \\
(\boldsymbol{\%})\end{array}$ & $\begin{array}{c}\text { TOC dissolution } \\
(\%)\end{array}$ \\
\hline \multirow{2}{*}{ Alginate } & DIW & 0.09 & ND & ND \\
entrapped nZVI & Day 1 FWW & 0.75 & 0.004 & ND \\
& Day 90 FWW & 3.18 & 0.025 & ND \\
\hline \multirow{2}{*}{ PVA-alginate } & DIW & 0.84 & ND & 2.09 \\
entrapped nZVI & Day 1 FWW & 2.89 & 0.002 & 10.1 \\
& Day 90 FWW & 7.07 & 0.026 & 17.5 \\
\hline
\end{tabular}

Note: ND stands for non-detectable 

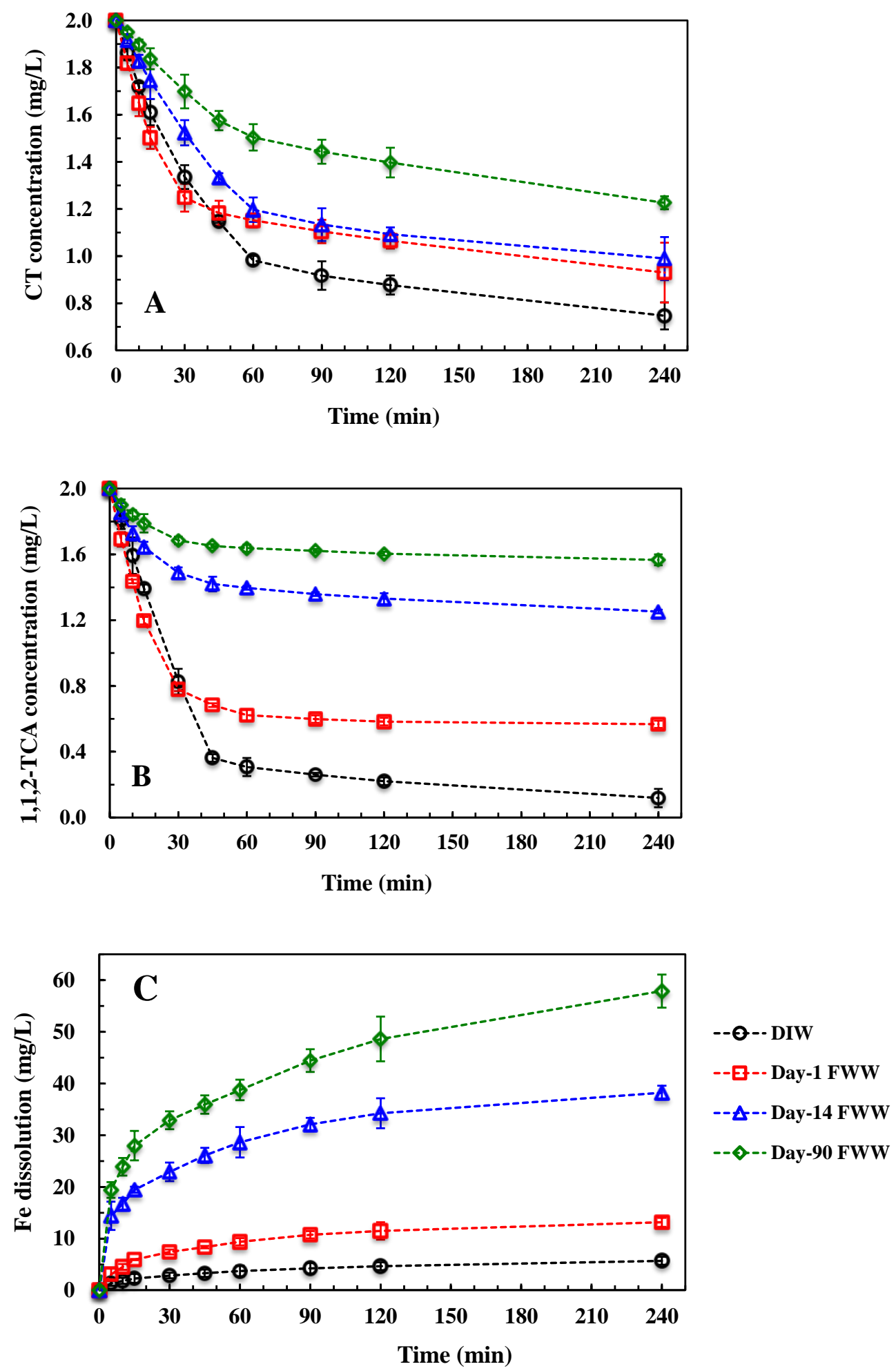

Figure 1. CT (A) and 1,1,2-TCA (B) degradation by bare nZVI in DIW, Day-1, Day-14 and Day-90 fracturing wastewater. Average Fe dissolution from nZVI during the 4-h reaction for CT and 1,1,2-TCA removal from DIW, Day-1, Day-14 and Day-90 fracturing wastewater (C). 

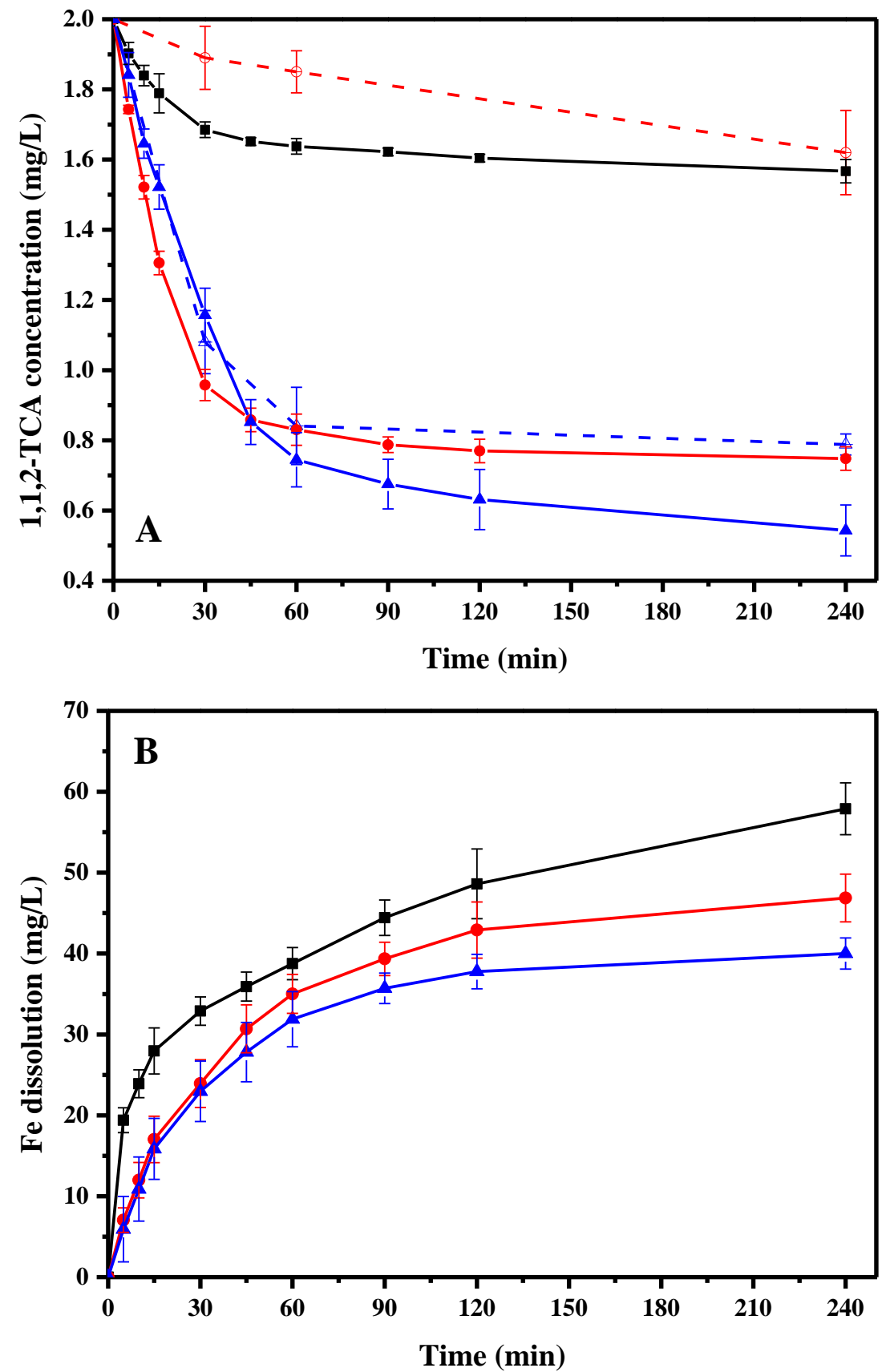

- $\oplus$ - alginate beads

- 4 - PVA-alginate beads

$\longrightarrow$ alginate entrapped nZVI

— PVA-alginate entrapped nZVI

$\longrightarrow$ bare nZVI

Figure 2. 1,1,2-TCA removal by bare and entrapped nZVI in Day-90 fracturing wastewater (A) and Fe dissolution from entrapped nZVI during the 4-h reaction (B). 

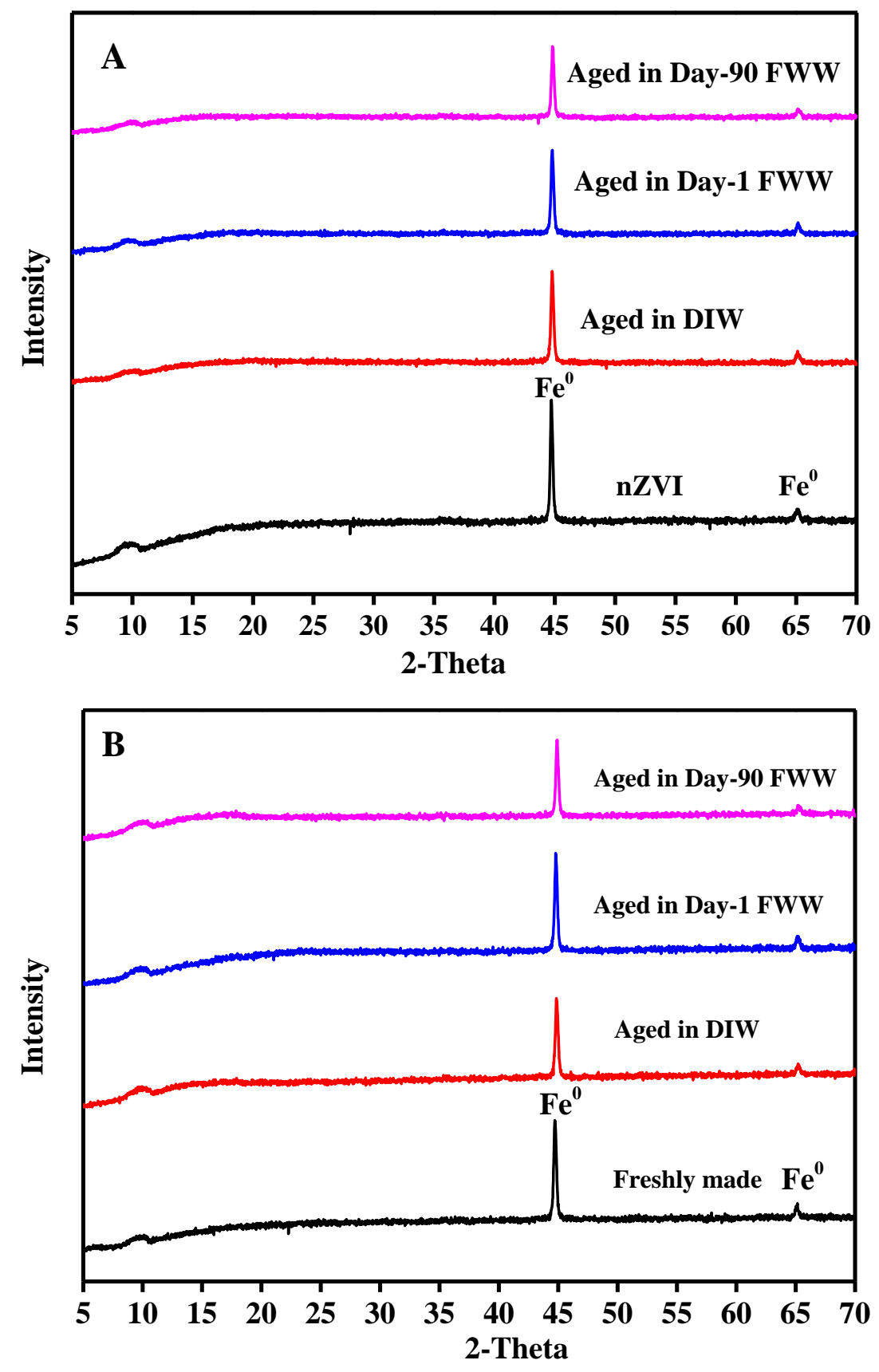

Figure 3. XRD spectra of alginate entrapped nZVI (A) and PVA-alginate entrapped nZVI (B) after 1-month aging in DIW, Day-1 and Day-90 fracturing wastewater 


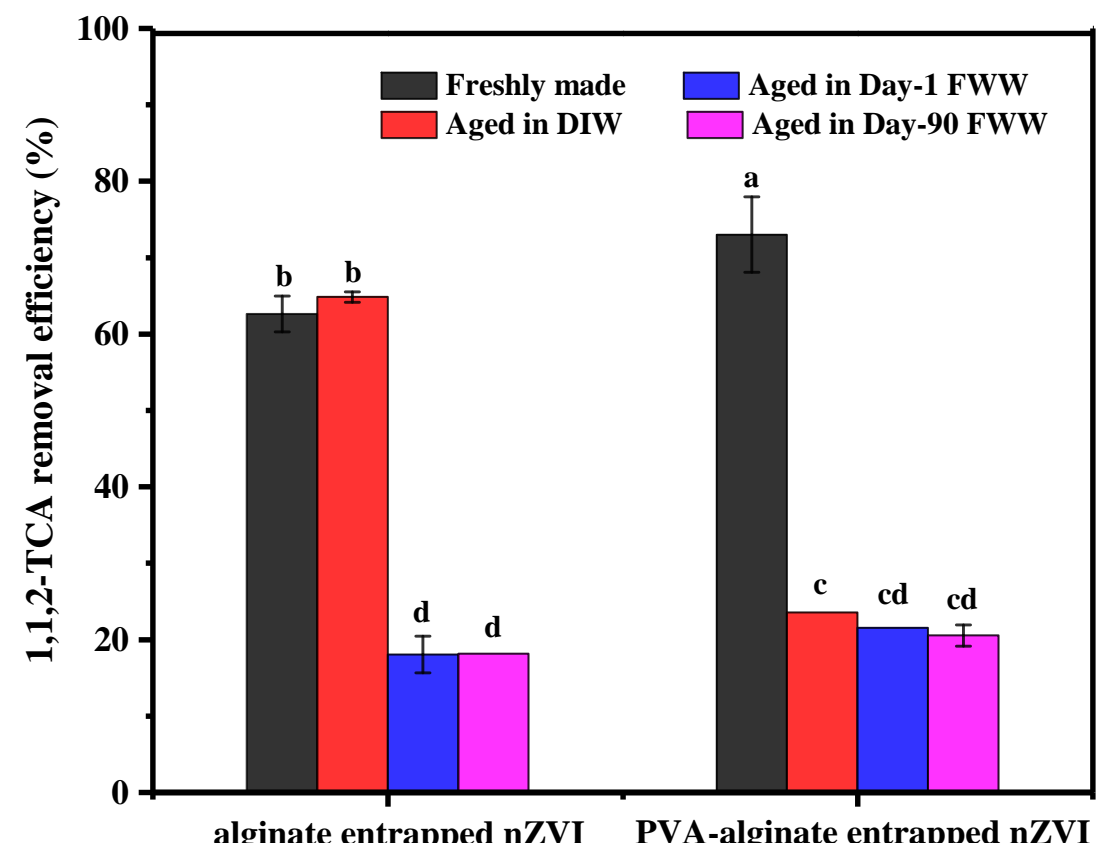

Figure 4. 1,1,2-TCA removal efficiency of aged entrapped nZVI in Day-90 fracturing wastewater after 4-h reaction (different letters indicate significant difference). 